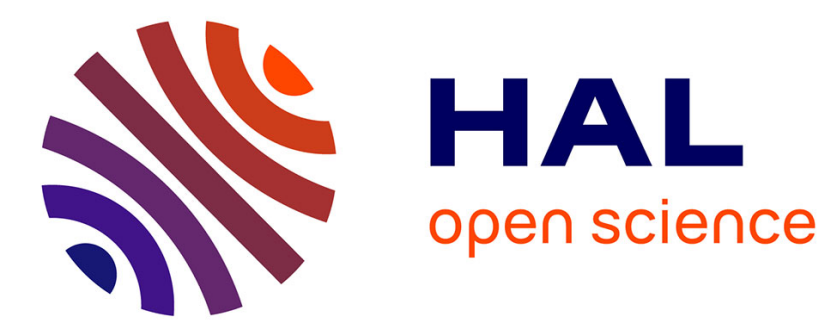

\title{
Locating ettringite due to DEF at the pore scale of cement paste by heat-based dissolution tests
}

Yushan Gu, Othman Omikrine Metalssi, Renaud Pierre Martin, Teddy Fen

Chong, Patrick Dangla

\section{- To cite this version:}

Yushan Gu, Othman Omikrine Metalssi, Renaud Pierre Martin, Teddy Fen Chong, Patrick Dangla. Locating ettringite due to DEF at the pore scale of cement paste by heat-based dissolution tests. Construction and Building Materials, 2020, 258, 19 p. 10.1016/j.conbuildmat.2020.120000 . hal$02923581 \mathrm{v} 2$

\section{HAL Id: hal-02923581 \\ https://hal.science/hal-02923581v2}

Submitted on 8 Sep 2020

HAL is a multi-disciplinary open access archive for the deposit and dissemination of scientific research documents, whether they are published or not. The documents may come from teaching and research institutions in France or abroad, or from public or private research centers.
L'archive ouverte pluridisciplinaire HAL, est destinée au dépôt et à la diffusion de documents scientifiques de niveau recherche, publiés ou non, émanant des établissements d'enseignement et de recherche français ou étrangers, des laboratoires publics ou privés. 


\title{
Locating ettringite due to DEF at the pore scale of cement paste by heat-based dissolution tests
}

\author{
Yushan GUa , Othman OMIKRINE METALSSI ${ }^{\mathrm{a}}$, Renaud-Pierre MARTIN ${ }^{\mathrm{b}}$, Teddy \\ FEN-CHONG ${ }^{\mathrm{a}}$, Patrick DANGLA ${ }^{\mathrm{c}, *}$ \\ ${ }^{a}$ MAST-FM2D, Univ Gustave Eiffel, IFSTTAR, F-77447 Marne-la-Vallée, France \\ ${ }^{b} M A S T-E M G C U$, Univ Gustave Eiffel, IFSTTAR, F-77447 Marne-la-Vallée, France \\ ${ }^{c}$ Navier, Ecole des Ponts, Univ Gustave Eiffel, CNRS, F-77447 Marne-la-Vallée, France
}

\begin{abstract}
An innovative experimental method, based on the thermal stability of ettringite, is proposed and implemented to dissolve the crystalline products formed during Delayed Ettringite Formation (DEF). The tests are designed to empty all the pores that are filled by ettringite during their formation. By characterising the porous structure before and after the heat-based dissolution test (HBDT) via Mercury Intrusion Porosimetry (MIP), it is proved that the pores filled by ettringite during DEF in the pore size range between 4 and $30 \mathrm{~nm}$ are emptied and that the pore size distribution (PSD) in this range is reversed, approaching the initial state (i.e. before the degradation induced by DEF). This observation helps to confirm the location of ettringite formed during DEF.

Keywords: Sulfate attacks, cement pastes, Delayed Ettringite Formation, pore size distribution, mercury intrusion porosimetry.
\end{abstract}

\section{Introduction}

Delayed Ettringite Formation (DEF) is observed when cementitious materials experience elevated temperatures during curing, either from a preheating treatment (PHT) or from an internal high temperature due to the heat of hydration in massive concrete elements. The primary ettringite is 5 believed to be decomposed under this elevated temperature when it is approximately above $65^{\circ} \mathrm{C}$ [1, 2, 3, leading to a release of sulfate ions in the pore solution. Part of these ions are adsorbed on

\footnotetext{
* Corresponding author

Email addresses: yushanjoanna@hotmail.com (Yushan GU), othman.omikrine-metalssi@univ-eiffel.fr (Othman OMIKRINE METALSSI), renaud-pierre.martin@univ-eiffel.fr (Renaud-Pierre MARTIN), teddy.fen-chong@univ-eiffel.fr (Teddy FEN-CHONG), patrick.dangla@ifsttar.fr (Patrick DANGLA)
} 
C-S-H, which may react with aluminate ions to once again form ettringite after cooling at ambient temperature [1]. Therefore, ettringite crystallisation in the gel pores of C-S-H is believed to be the cause of the expansion of cement paste, something that has been confirmed in [4, 5]. Additionally, the evolution of the pore size distribution (PSD) of cement paste specimens exposed to DEF was investigated in [5], from which it was concluded that ettringite precipitates preferentially in big capillary pores (larger than 100nm) without generating an obvious expansion, while leading to a large one when it forms in smaller capillary and gel pores (less than 100nm) in a second stage.

In the studies concerning $\mathrm{DEF}$, it is admitted that a curing temperature above $65^{\circ} \mathrm{C}$ is essential to decompose the ettringite formed in the cementitious material during the early-age hydration [1, 6, 1, 8, 9, 10, 11]. It is noted that the water content of ettringite drops from 32 to 10 molecules at $70.5^{\circ} \mathrm{C}$ [12, and that ettringite remains stable when it loses from 32 to 18 water molecules. However, the crystal starts to disintegrate when the water molecules drop from 18 to less [13, 14]. A higher curing temperature tends to decompose ettringite more and faster [15]. However, a pessimum effect has been reported in the literature, e.g. in [3]: for a given exposure duration, it means that the final expansion increases with the increasing temperature up to a certain value, beyond which the expansion decreases; for a given exposure temperature, a pessimum effect can be observed above a certain exposure duration. The instability of ettringite at a temperature above $65^{\circ} \mathrm{C}$ inspired us to propose a way to "remove" precipitated ettringite crystals in cementitious materials. However, a high temperature may also decompose and change phases of other hydrate products. The temperatures at which cement hydrates may decompose or change phases are summarized in [16, which helps to identify the phase changes due to high temperatures. At temperatures between 50 and $100^{\circ} \mathrm{C}$, only ettringite and C-S-H start to decompose or be transformed into other phases, which changes the porous structure of the material. However, in [17, it is pointed out that AFt loses its crystalline form around $80^{\circ} \mathrm{C}$ and that no ettringite could be detected at $100^{\circ} \mathrm{C}$, while C-S-H disappears completely around $400^{\circ} \mathrm{C}$ and loses only around $20 \%$ in mass at $100^{\circ} \mathrm{C}$ due to its dehydration. Therefore, it is reasonable to believe that at high temperatures, between 65 and $100^{\circ} \mathrm{C}$, ettringite would be the main phase that decomposes or changes.

This paper aims at setting up an experimental method, based on the fact that ettringite is unstable at temperatures between 65 and $100^{\circ} \mathrm{C}$, to empty the pores that are filled by DEF-induced ettringite, and furthermore, to confirm that the presence of ettringite is the reason explaining the expansion during DEF. To reach this objective, the effect of different heating temperatures and durations on 
the PSD of DEF-damaged cement pastes will be investigated in this study.

\section{Materials and heat-based dissolution tests}

40

2.1. Materials, casting and curing

Table 1: Composition of the cement CEM I.

\begin{tabular}{|c|c|c|c|c|c|c|c|c|c|c|c|c|c|c|c|}
\hline $\begin{array}{c}\text { Components } \\
(\%)\end{array}$ & $\mathrm{CaO}$ & $\mathrm{SiO}_{2}$ & $\mathrm{Al}_{2} \mathrm{O}_{3}$ & $\mathrm{TiO}_{2}$ & $\mathrm{Fe}_{2} \mathrm{O}_{3}$ & $\mathrm{MgO}$ & $\mathrm{SO}_{3}$ & $S$ & $\mathrm{~K}_{2} \mathrm{O}$ & $\mathrm{Na}_{2} \mathrm{O}$ & $\mathrm{Cl}$ & $\mathrm{MnO}$ & $\begin{array}{l}\text { LOI (Loss } \\
\text { on ignition) }\end{array}$ & Insoluble & $\begin{array}{l}\text { Free } \\
\text { lime }\end{array}$ \\
\hline CEM I & 62.79 & 20.38 & 4.30 & 0.24 & 3.80 & 1.25 & 3.46 & Traces & 0.73 & 0.35 & 0.04 & 0.05 & 2.04 & 0.54 & 1.39 \\
\hline
\end{tabular}

Table 2: Composition of CEM I calculated by the Bogue method, based on information in Tab1

\begin{tabular}{|c|c|}
\hline Components & Mass content from Bogue method\% \\
\hline $\mathrm{C}_{3} \mathrm{~S}$ & 41.45 \\
\hline $\mathrm{C}_{2} \mathrm{~S}$ & 27.15 \\
\hline $\mathrm{C}_{3} \mathrm{~A}$ & 4.97 \\
\hline $\mathrm{C}_{4} \mathrm{AF}$ & 11.54 \\
\hline $\mathrm{C} \overline{\mathrm{S}} \mathrm{H}_{2}$ & 7.44 \\
\hline
\end{tabular}

A set of four specimens were fabricated with CEM I 52.5 R CE CP2 NF cement [18] with a size of $11 \times 11 \times 22 \mathrm{~cm}^{3}$. Its chemical composition is presented in Tab 1 and 2 [19]. After the casting, specimens were protected during their moist cure with a curing textile on the top surfaces to prevent the leaching of ions, and they were exposed to high temperatures at the early age in a tank with water inside; the procedure used (referred to as "PHT" in the following) was proposed in 20] and can be summarised as:

- Setting specimens aside for $2 \mathrm{~h}$ as pre-curing;

- Increasing the temperature up to $81^{\circ} \mathrm{C}$ after $24 \mathrm{~h}$ with a maximum rate of about $10^{\circ} \mathrm{C} / \mathrm{h}$;

- Keeping a constant temperature of $81^{\circ} \mathrm{C}$ for $72 \mathrm{~h}$;

${ }_{50}$ - Decreasing the temperature to $25^{\circ} \mathrm{C}$ with a rate of $-1^{\circ} \mathrm{C} / \mathrm{h}$.

The preheating history is illustrated in Fig 1 . After the PHT, the specimens were demolded and kept under the aluminum sealing for 28 days to keep the moisture constant in the specimens. This ensures a continuous hydration and limits the effect of leaching as compared to a continuous storage in water. After the curing period, the specimens were kept in tap water without any renewal, with ${ }_{55}$ a water to sample ratio (volume of stored water / volume of specimens) of around 3. 


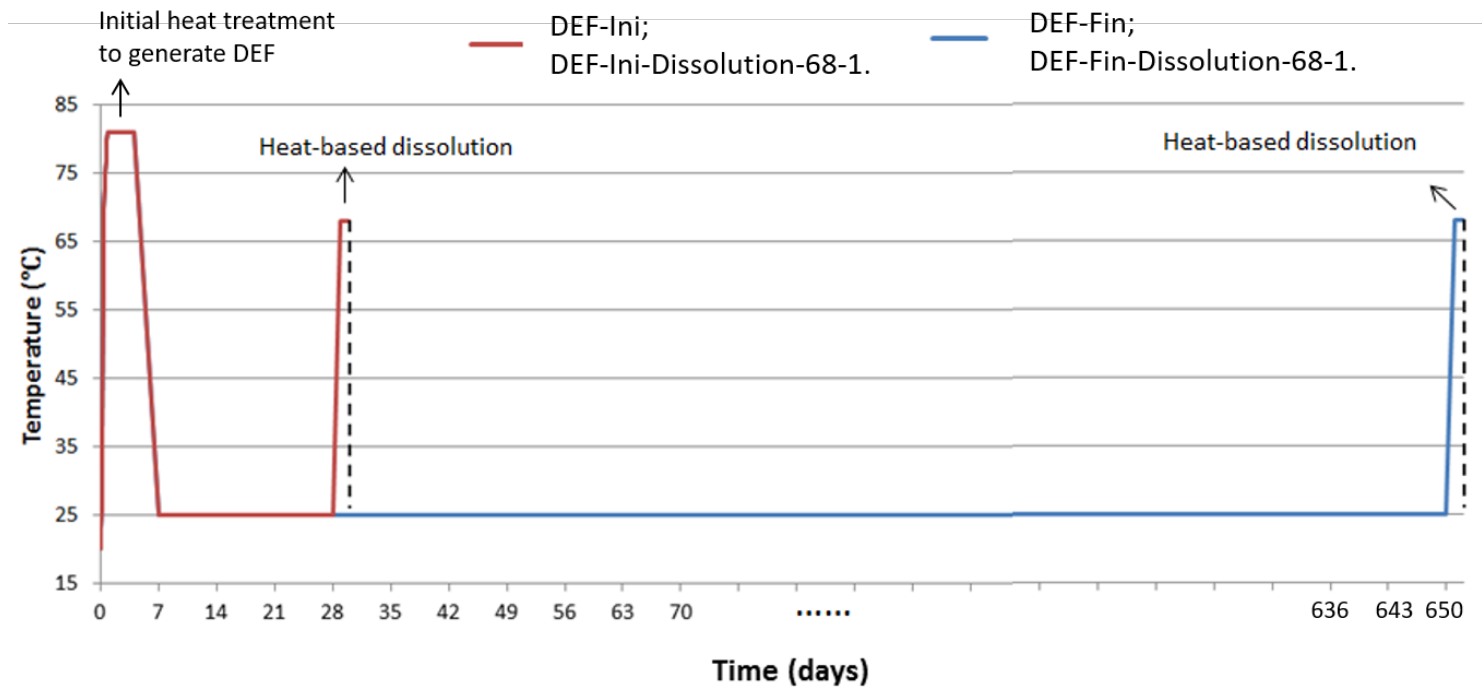

Figure 1: Evolution of the heat treatment with time.

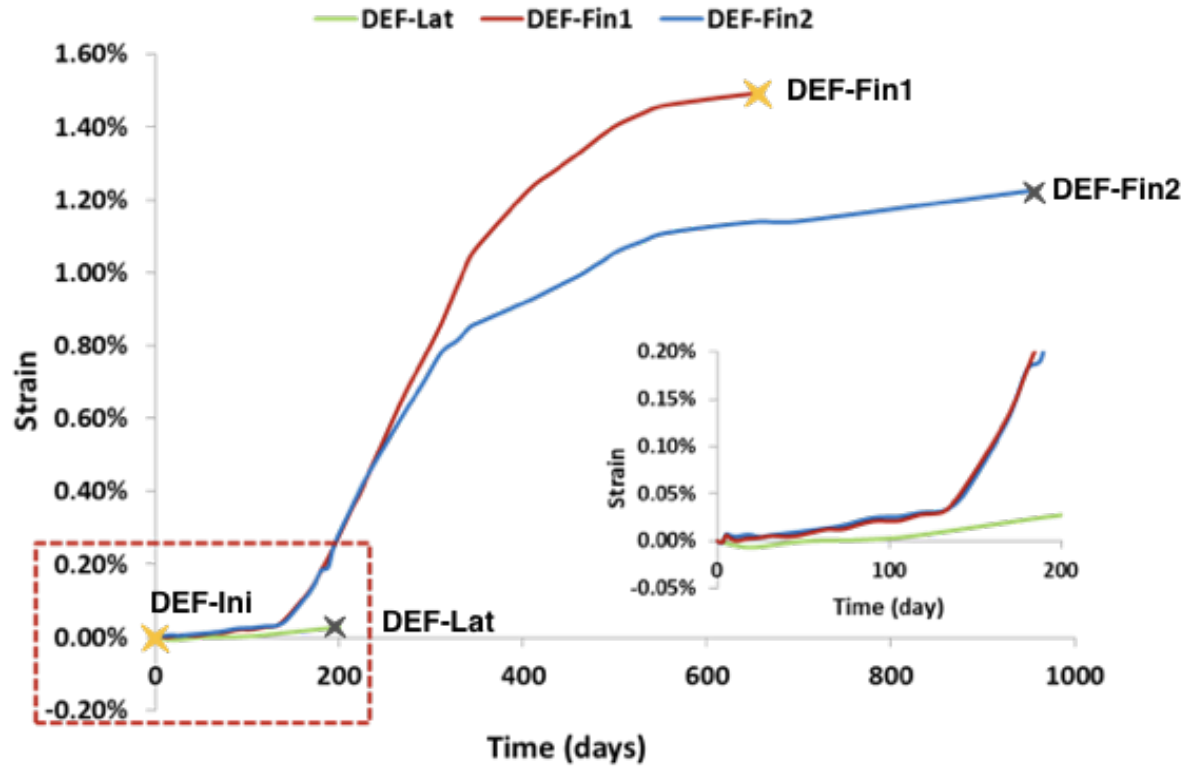

Figure 2: The expansion curve of the specimens exposed to DEF [5] (time zero in this figure corresponds to the moment after a 28-day curing). 
The exposure of the specimens to tap water was stopped at different times, and four specimens were characterised at different degradation states (see Fig2):

- the initial state (after a 28-day curing, including the PHT that generates the DEF potential). It is marked as 0 day in Fig,2

- the latent period (specimen DEF-Lat has an expansion up to $0.03 \%$, after about 200 days);

- two final states with different expansion degrees: specimen DEF-Fin1 has an expansion up to $1.49 \%$ after 650 days, and specimen DEF-Fin2 has an expansion of $1.22 \%$ after 950 days.

One important information has to be recalled: the fact that the former two specimens (DEF-Ini and DEF-Lat) were cast with a specific mortar mixer while the latter two specimens were fabricated with a 30-L concrete mixer. Moreover, a different mixing procedure was followed for them.

In this study, two specimens: DEF-Ini and DEF-Fin1, are selected, which are marked in yellow in Fig 2 The specimen DEF-Fin1 is selected for the qualification of the HBDT, and the DEF-Ini specimen is selected as a reference of the sound state of the material.

\subsection{Samples preparation}

When a cementitious material is exposed to solutions, leaching happens, which starts from the exposure surface to the core. In addition, the exposed surface of specimens has the most serious degradation 21. In our study, in order to limit the effect of leaching on the measurement results, samples in the core layer (at depth between $5-5.5 \mathrm{~cm}$ from the surface of the specimens in the transversal direction) were selected, see Fig, Then the core layer of the specimen was ground roughly into particles, each particle having a mass of approximately $0.4 \mathrm{~g}$. Some of the particles were prepared for Mercury Intrusion Porosimetry (MIP) tests, for instance, samples before the HBDT: DEF-Ini and DEF-Fin1, and the remaining samples were submitted to the HBDT.

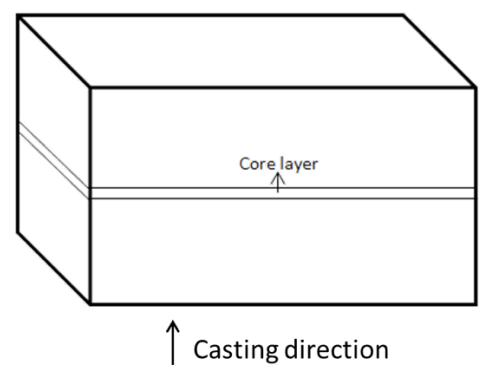

Figure 3: Slicing schemes for prisms. 


\subsection{Heat-based dissolution tests}

Since ettringite becomes unstable at temperatures above $65^{\circ} \mathrm{C}$ and the fact that ettringite decomposes more and faster under a higher curing temperature, a set of temperatures $(68,78,88$, and $98^{\circ} \mathrm{C}$ ) was chosen, as well as different durations (1, 3, 5, 7 and 11 days). Tab 3 shows the samples, the temperatures and the durations chosen for the test. The DEF-Fin1 samples were exposed to four temperatures with two durations: 1 day and 3 days, as well as three more durations $(5,7$, and 11 days) at a temperature of $68^{\circ} \mathrm{C}$. Moreover, the DEF-Ini samples were heated at $68^{\circ} \mathrm{C}$ for 1 day, as a reference.

Table 3: Temperatures and durations used in the HBDT

\begin{tabular}{|c|c|c|c|c|c|}
\hline DEF-Fin1 & 1 day & 3 days & 5 days & 7 days & 11 days \\
\hline $68{ }^{\circ} \mathrm{C}$ & $\sqrt{ }$ & $\sqrt{ }$ & $\sqrt{ }$ & $\sqrt{ }$ \\
\hline $78^{\circ} \mathrm{C}$ & $\sqrt{ }$ & $\sqrt{ }$ & & \\
\hline $88^{\circ} \mathrm{C}$ & $\sqrt{ }$ & $\sqrt{ }$ & & \\
\hline $98^{\circ} \mathrm{C}$ & $\sqrt{ }$ & $\sqrt{ }$ & & \\
\hline DEF-Ini & & & & & \\
\hline $68^{\circ} \mathrm{C}$ & $\sqrt{ }$ & & & & \\
\hline
\end{tabular}

The samples are named according to the expansion state of the specimen (DEF-Ini, and DEF-Fin1), the heating temperature used for the dissolution tests in ${ }^{\circ} \mathrm{C}(68,78,88$, and 98), and the heating duration in days $(1,3,5,7$, and 11). To limit the leaching during the HBDT, the samples were immersed in the storage water of the DEF-Fin1 specimen during heating: indeed, after a 2-year storage of DEF specimens, the storage solution contains calcium ions and other alkalis, and thus limits further leaching.

Firstly, the DEF-Ini sample was heated at $68^{\circ} \mathrm{C}$ for 1 day to study the effect of high temperatures on the PSD of the sound samples that have no DEF-induced ettringite. By this way the effect of high temperatures on the microstructure of the DEF-Ini samples (without ettringite) is investigated. The results provide a reference to analyse the effect of high temperatures on the microstructure of the DEF-Fin samples (DEF-induced crystals included). Secondly, the DEF-Fin1 samples were heated at high temperatures. The effect of the heating temperatures and durations were investigated. The heating histories of the specimens are shown in Fig 1 . 


\subsection{Freeze-drying method and MIP measurements}

When the samples were ready for the characterisation of the microstructure, a freeze-drying method procedure was initiated. The samples were put in a container filled with liquid nitrogen inside for approximately 5 minutes, and were put in a freeze-dryer for 3 days afterwards. The water inside the materials was transformed into steam by heating up the water in a frozen state under very low air pressure conditions (0.07mbar). Then, the released steam was caught up in a cooling coil at a temperature of $-57^{\circ} \mathrm{C}$ and removed. Freeze-drying method is an efficient method to dry materials without changing their microstructure significantly, and the minor change of the microstructure created in the procedure could be ignored in this comparative study. After the freeze-drying method procedure, the samples were prepared for the MIP tests to obtain the PSD. For each test, samples of around $1 \mathrm{~g}$ were selected. The instrument used is a Micromeritics' AutoPore IV 9500 series Porosimeter, which allows the investigation of a pore size range between $3.7 \mathrm{~nm}$ and $400 \mu \mathrm{m}$.

\section{Results and analyses}

In this section, the PSD of samples, before and after the HBDT via MIP, are presented and compared. To better analyse the variation of the microstructure, a brief literature review will first be proposed.

\subsection{Evidence from the literature of the effect of temperature on the microstructure and composition} of cement paste

When a cement-based material is exposed to high temperatures, the most important processes that occur include chemical reactions, phase transformations and heat deformations occurring at a microscopic scale [22]. In [23, the microstructure of pastes cured at $60^{\circ} \mathrm{C}$ showed a greater porosity than those cured at $10^{\circ} \mathrm{C}$, something which can be explained by a higher thermal expansion of anhydrates and portlandite compared to the shrinkage of hydrates 24]. The dilation of the pores and the existence of microcracks are other possible reasons explaining the higher porosity at high temperatures, and the affected pore size range is larger than $100 \mathrm{~nm}$ according to [25, 26]. However, in [24, the total porosity of gel and capillary pores was found to be stable when heated up to $300^{\circ} \mathrm{C}$ due to the fact that the shrinkage of the cement paste [22] is counterbalanced by the additional hydration of unhydrated cement grains and the recrystallisation of $\mathrm{Ca}(\mathrm{OH})_{2}$. An increase of $\mathrm{CH}$ of around $1 \%$ in mass has also been detected in [27] when cementitious materials are exposed to 
increasing temperatures from 20 to $200^{\circ} \mathrm{C}$, due to the progress of the hydration of residual anhydrous components. Indeed, the solubility of portlandite decreases as the temperature increases. For instance, the solubility constant of $\mathrm{Ca}(\mathrm{OH})_{2}$ is approximately $2.15 \times 10^{-6}$ at a room temperature of $23^{\circ} \mathrm{C}$, and it decreases to $7.83 \times 10^{-7}$ when the temperature increases up to $100^{\circ} \mathrm{C}[28$.

To sum up, the variation of the PSD of cement paste during this HBDT is believed to be caused by:

- the microcracks of size larger than (around) 100nm due to the heating [25, 26];

- the formation of $\mathrm{Ca}(\mathrm{OH})_{2}$ either from the additional hydration of residual anhydrous components 27] or from the recrystallisation of amorphous $\mathrm{Ca}(\mathrm{OH})_{2}$ [24];

- the dissolution of AFt.

The PSD of the samples before and after the HBDT via MIP are presented and compared in the following sections.

The PSD of $11 \times 11 \times 22 \mathrm{~cm}^{3}$ DEF-Ini and DEF-Fin1 samples, are given in Fig 4 (a). It can be concluded that after DEF, pores between 4 and 30nm are filled by ettringite (red zone in Fig 4 (a)), and the pore volume increases between 100nm and $10 \mu \mathrm{m}$ (dark yellow zone in Fig,4(a)), which may be caused by the dissolution of portlandite [29, 30, 31, 32] and the generation of microcracks [26, 33].

One information first has to be reminded: there are four possible processes during DEF, which may affect the microstructure of cement materials: AFt formation, the dissolution of $\mathrm{CH}$, the decalcification of CSH, and the occurrence of microcracks. However, only "AFt formation" leads to a decrease of the pore volume. The PSD evolution observed is therefore a "competitive" result upon these four processes. For instance, the decrease of the pore volume in the pore range of $4-30 \mathrm{~nm}$ does not necessarily mean that no other processes occur, but that the dissolution of $\mathrm{CH}$ and the decalcification of CSH lead to a less volume, compared to the occupied pore space due to the AFt formation. 


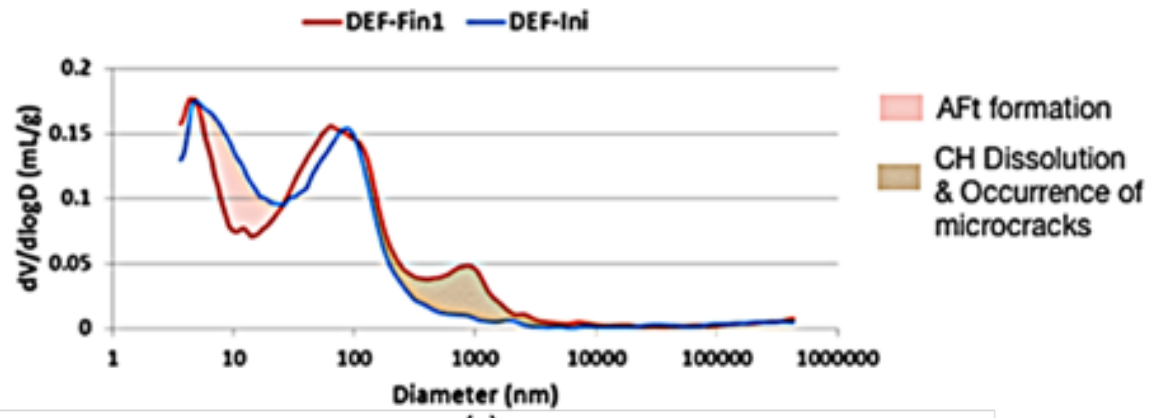

(a)

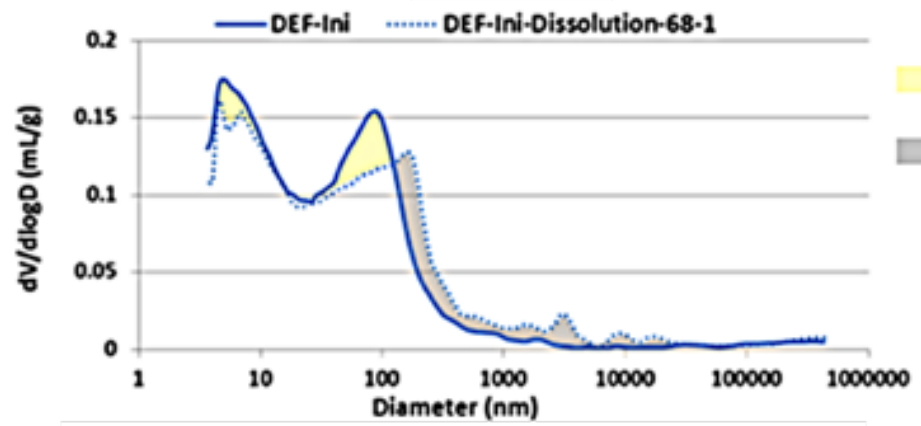

$\mathrm{CH}$ formation

Occurrence of

microcracks

(b)

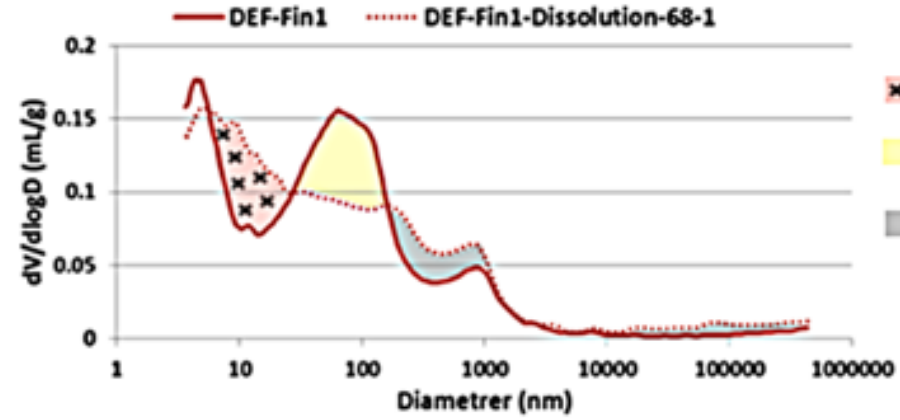

$\times \times$ AFt dissolution

$\mathrm{CH}$ formation

Occurrence of

microcracks

(c)

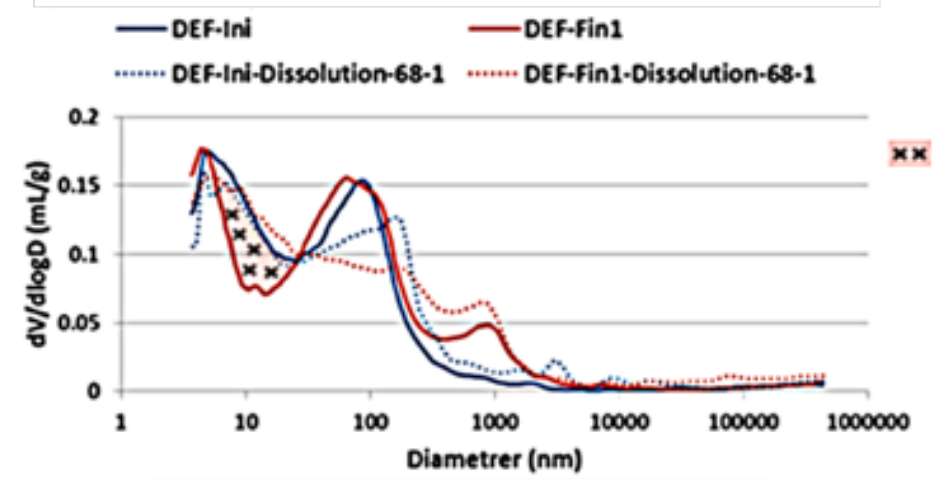

(d)

Figure 4: PSD of (a) DEF-Fin1 \& DEF-Ini before HBDT; (b) sound specimens: DEF-Ini \& DEF-Ini-Dissolution-681 before and after HBDT; (c) DEF-damaged specimens: DEF-Fin1 \& DEF-Fin1-Dissolution-68-1 before and after HBDT; and (d) all the specimens above. 
The aim of the HBDT is to dissolve the precipitated ettringite induced by DEF, specifically, to empty the pores filled by these crystals. Therefore, the following analyses will focus more on the pore size range of $4-30 \mathrm{~nm}$, where ettringite is found precipitated in Fig 4 (a).

\subsection{Microstructure of samples heated at $68^{\circ} \mathrm{C}$ for 1 day}

Fig,4(b) shows that after a 1-day heating at $68^{\circ} \mathrm{C}$, the pore volume in the pores larger than $130 \mathrm{~nm}$ increases and the pore volume with respect to diameters less than 130nm decreases (respectively, the grey and yellow zones in Fig, $4(\mathrm{~b}))$. The reason explaining the increase of the pore volume in the grey zones is the extension of microcracks [25, 26] due to the high temperatures, and the decrease of the pore volume in the yellow zones is caused by the formation of $\mathrm{CH}$. There are two possible reasons explaining the formation of $\mathrm{CH}$. One is the recrystallisation of amorphous $\mathrm{Ca}(\mathrm{OH})_{2}$ [24], as the solubility of portlandite decreases with increasing temperatures. Another reason is that during the immersion in the solution at $68^{\circ} \mathrm{C}$, additional hydration 27] occurs, since the DEF-Ini specimen is selected after the 28-day curing and the hydration is not completely finished. This provides a reference to study the effect of high temperatures on the microstructure of the DEF-Fin1 specimen. Specifically, the high temperature, at $68^{\circ} \mathrm{C}$, leads to the formation of $\mathrm{Ca}(\mathrm{OH})_{2}$ (in the range less than $130 \mathrm{~nm}$ ) and the extension of microcracks [25, 26].

The PSD of the DEF-Fin1 and DEF-Fin1-Dissolution-68-1 (DEF-Fin1 samples heated at $68^{\circ} \mathrm{C}$ for 1 day) are shown in Fig 4 (c). Based on the analyses of Fig $4(\mathrm{~b})$, the formation of $\mathrm{Ca}(\mathrm{OH})_{2}[24,27$, and the extension of microcracks should occur during the exposure to high temperatures, which are indeed observed on the DEF-Fin1-Dissolution-68-1 samples. Moreover, the pore space between 8 and 30nm, which was occupied by the precipitated ettringite during DEF (shown in Fig 4(a)), is released. This can be explained by the dissolution of ettringite. However, the dissolution of AFt may be accompanied by the formation of $\mathrm{Ca}(\mathrm{OH})_{2}$, which could not be confirmed from these results.

A general comparison of all the samples above is presented in Fig $4(\mathrm{~d})$. It is clearly shown that after being heated at $68^{\circ} \mathrm{C}$ for 1 day, the PSD between 8 and 30nm approaches those in the two initial samples (DEF-Ini and DEF-Ini-Dissolution-68-1). For a better understanding, the variation of the porosity of these samples is presented in Fig 5 . The entire pore range is classified into four parts, according to the main variations. It clearly shows that the porosity in the pore range of $8-30 \mathrm{~nm}$ decreases from 8.4\% (DEF-Ini) to 6.2\% (DEF-Fin1) after DEF, and further increases to $9.2 \%$ when 
DEF-Fin1 has been exposed to the HBDT at $68^{\circ} \mathrm{C}$ for 1 day. Moreover, a decrease of the pore volume with respect to diameters between 30 and $130 \mathrm{~nm}$, and an increase of the pore volume in the pore range of $130 \mathrm{~nm}-400 \mu \mathrm{m}$ are observed in two heated samples (DEF-Ini-Dissolution-68-1 and DEF-Fin1-Dissolution-68-1). These conclusions are consistent with the analyses shown above.

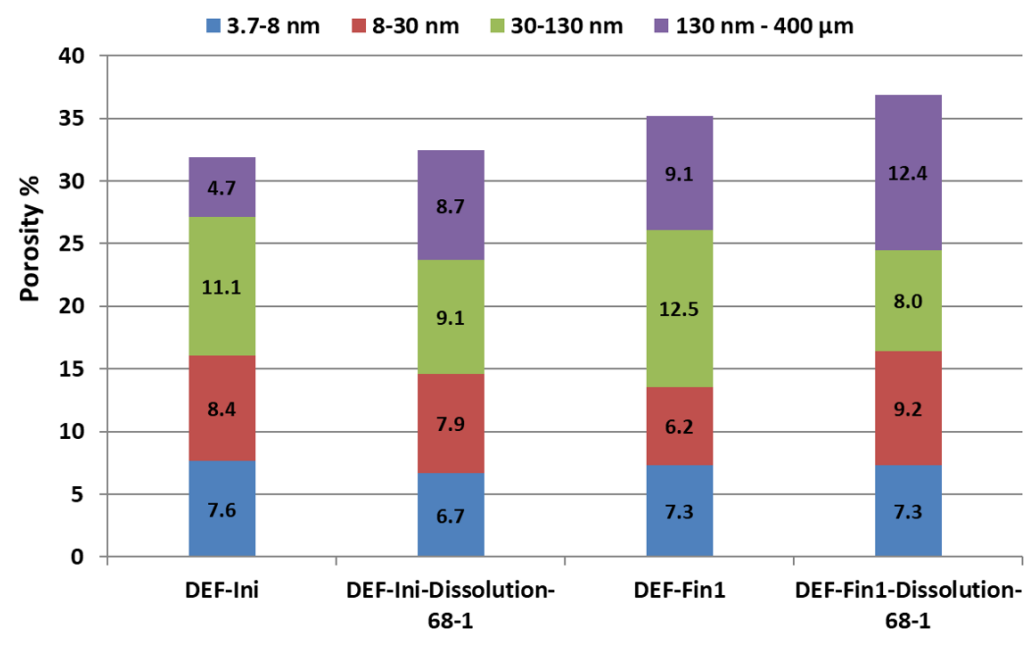

Figure 5: The variation of the porosity of samples: DEF-Ini, DEF-Ini-Dissolution-68-1, DEF-Fin1, and DEF-Fin1Dissolution-68-1.

Therefore, it is concluded that the PSD of the DEF-Fin1-Dissolution-68-1 sample between 8 and 30nm is reversed, approaching that of the initial samples: DEF-Ini and DEF-Ini-Dissolution-68-1.

It proves that the proposed HBDT is effective to dissolve the generated ettringite. 


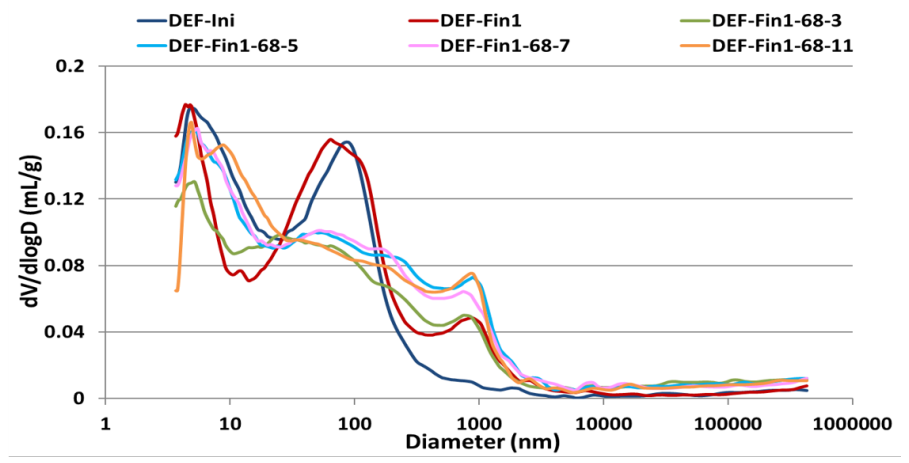

(a)

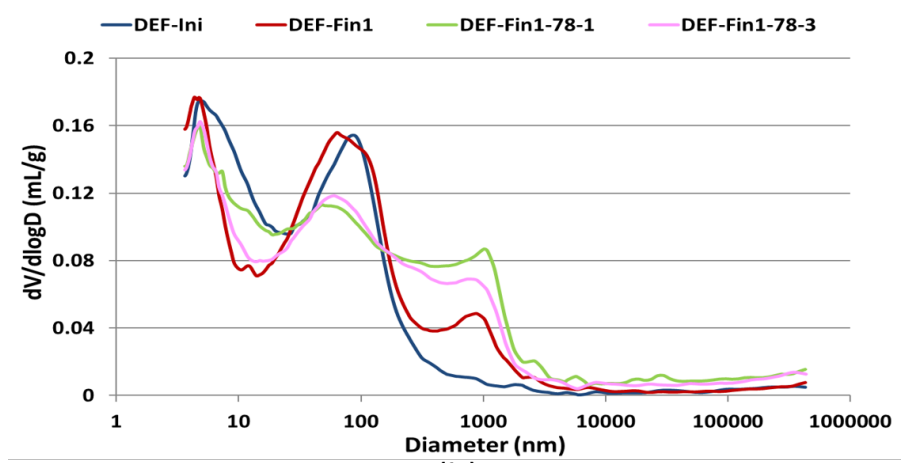

(b)

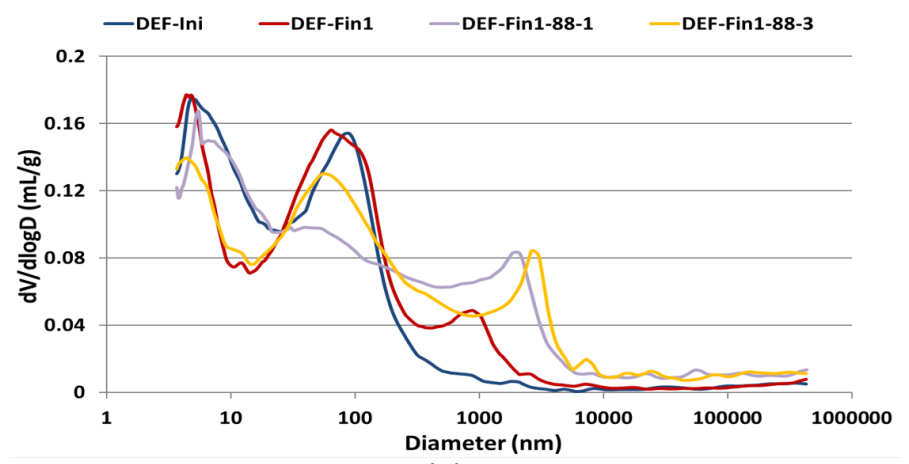

(c)

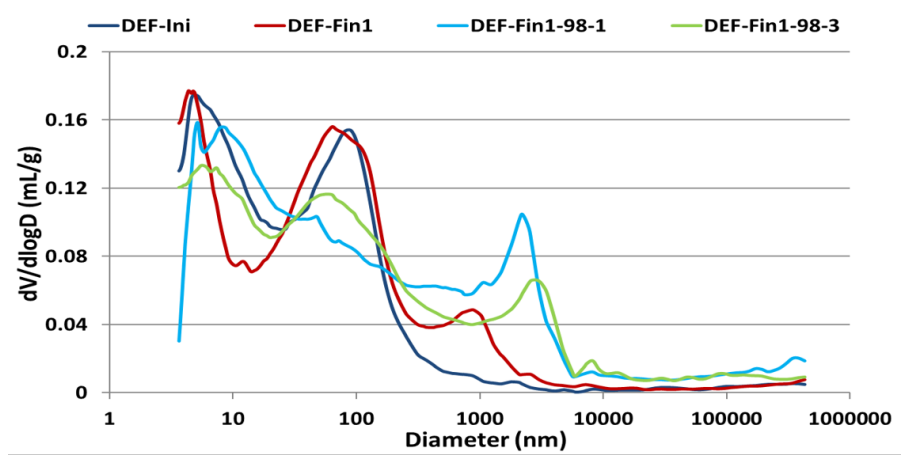

(d)

Figure 6: PSD measured from MIP before and after the HBDT at (a) $68^{\circ} \mathrm{C}$, (b) $78^{\circ} \mathrm{C}$, (c) $88^{\circ} \mathrm{C}$, and (d) $98^{\circ} \mathrm{C}$ 


\subsection{Microstructure of samples heated at different temperatures for different durations}

The PSD of cement paste exposed to different temperatures for different durations are shown in Fig 6 . Based on the analyses shown above, we will focus more on the pore size range between 8 and $30 \mathrm{~nm}$. It can be observed that the pores filled by ettringite during DEF are released after the HBDT, except for the DEF-Fin1-78-3 and DEF-Fin1-88-3 samples, and these exceptions can be explained by a "competition" between the dissolution of AFt and the precipitation of portlandite. For example, the DEF-Fin1-78-3 samples still have a quite similar PSD in the pore size range between 8 and 30nm after being heated, compared to the one before HBDT (DEF-Fin1). This may be caused by an equivalence between the volume released by the dissolution of AFt and the one filled by the crystallisation of portlandite. Moreover, the differences among these curves in Fig 6 (except for DEF-Fin1-78-3 and DEF-Fin1-88-3 samples) in the range between 8 and 30nm, are not significant and could be ignored, since MIP shows a highest relative variability of porosity measurements of $4 \%$, with an average standard error of $0.6 \%$, based on 30 measurements of the cement paste 34 .

According to the PSD of samples subjected to HBDT found in Fig 6 , a higher temperature tends to induce more microcracks in the material, where a higher pore volume is created in the pore size range around $1 \mu \mathrm{m}\left[25,26\right.$. Exposed to temperatures ranging from 68 to $98^{\circ} \mathrm{C}$, samples show a shift of the peak at the maximum pore size from around $1 \mu \mathrm{m}$ for the samples at 68 and $78^{\circ} \mathrm{C}$, to $2.6 \mu \mathrm{m}$ for the DEF-Fin1-98-1 samples and 3.21 $\mu \mathrm{m}$ for the DEF-Fin1-98-3 samples. Moreover, a longer exposure to high temperatures leads to a higher pore volume in the middle pore size range between 40 and $200 \mathrm{~nm}$, with a lower porosity in the two border ranges. The cause of these changes in the structure of cement gel probably is the liberation of chemically bounded water 24. The increase could also be attributed to the collapse of C-S-H gel microstructure upon the heating [35].

The variation of the porosity of samples exposed to high temperatures is illustrated in Fig,7. It is observed that heated samples release the pore space in the pore range of 8-30nm (except for DEF-Fin1-78-3 and DEF-Fin1-88-3 samples) in different degrees, and pores are occupied in the pore range of $30-130 \mathrm{~nm}$ due to $\mathrm{CH}$ formation. Moreover, the pores with respect to diameters larger than $130 \mathrm{~nm}$ are released as well, something that was explained by the occurrence of microcracks. The porosity of the samples that are heated with different temperatures for 1 day, in the pore range of $130 \mathrm{~nm}-400 \mu \mathrm{m}$, increases from $12.4 \%$ at $68^{\circ} \mathrm{C}$ to $17.8 \%$ at $98^{\circ} \mathrm{C}$. Therefore, it can be concluded that higher temperatures between $68-98^{\circ} \mathrm{C}$ lead to more microcracks in the cement paste. 


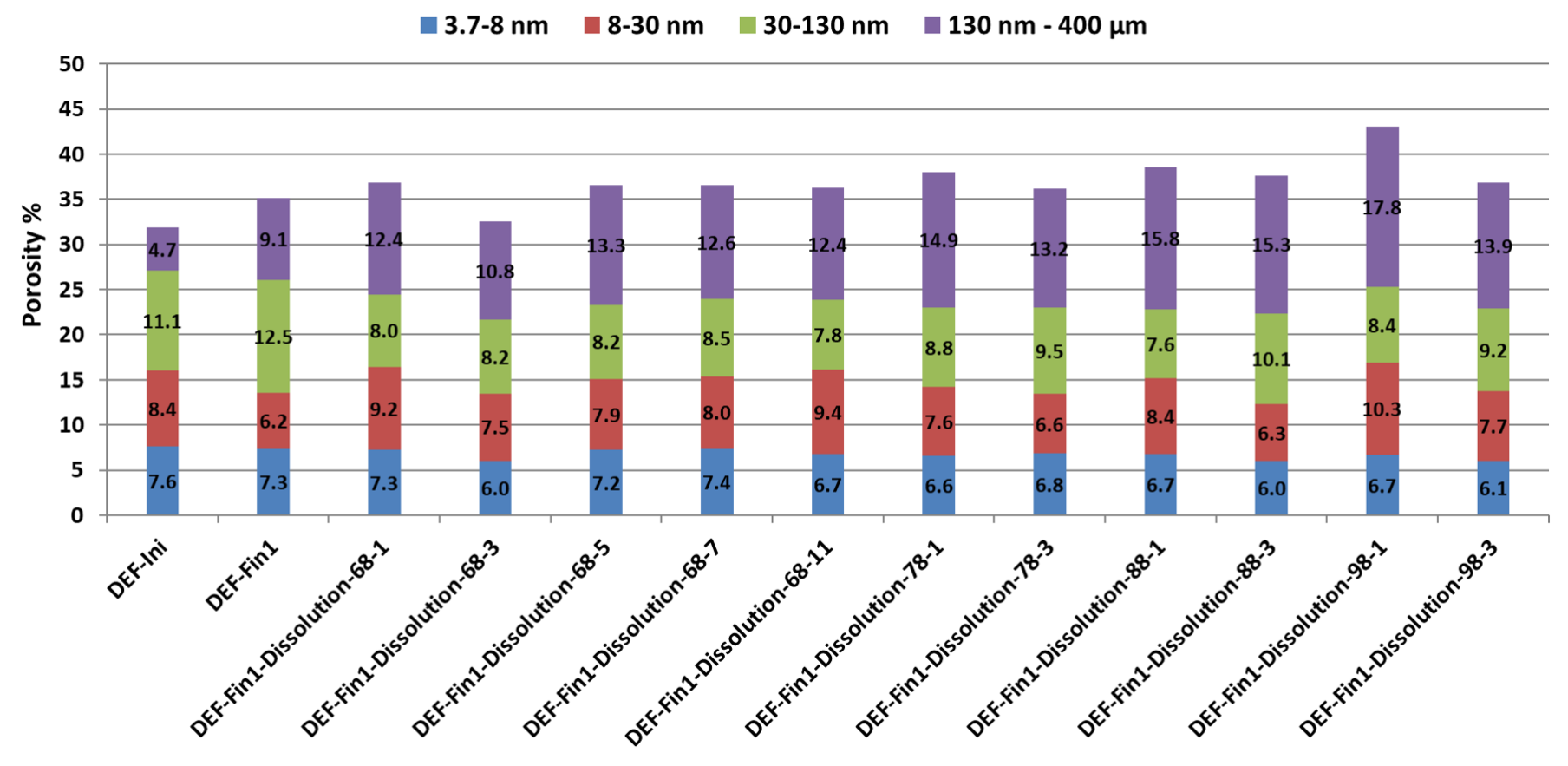

Figure 7: The variation of the porosity of samples heated at $68,78,88$, and $98^{\circ} \mathrm{C}$.

To summarise, it can be concluded that the heat-based dissolution at $68^{\circ} \mathrm{C}$ for 1 day is efficient enough to "wash" out the ettringite formed during the process of DEF, and avoid more microstructural changes in materials that may be generated by higher temperatures and longer heating durations, which in turn proves that the crystals formed in the pore range between 8 and 30nm during DEF are indeed ettringite crystals. This result contributes to confirm the mechanism of DEF that is proposed in [5: during the DEF, ettringite firstly precipitates in big capillary pores of cement paste specimens and no obvious expansion is observed, while a large expansion occurs when ettringite penetrates into smaller capillary pores and gel pores. According to the Laplace equation and the surface tension of ettringite, a gel pore of $10 \mathrm{~nm}$ in diameter can give rise to a crystallisation pressure of about $40 \mathrm{MPa}$, which exceeds the ultimate elastic stress of cement paste and consequently induces the microcracks. 


\section{Conclusions}

In our previous work [5], the DEF-generated ettringite was found to precipitate in materials in the pore size range between 4 and 30nm. When subsequently exposed to high temperatures, between 68 and $98^{\circ} \mathrm{C}$, for durations varying from 1 to 11 days, the PSD of DEF-damaged samples in the pore size range between 8 and $30 \mathrm{~nm}$ is reversed and approaches that of the initial samples. The porosity in the pore range of $8-30 \mathrm{~nm}$ decreases from $8.4 \%$ to $6.2 \%$ after DEF, and further increases to $9.2 \%$ when the DEF-damaged samples has been exposed to the HBDT (Heat-Based Dissolution Test) at $68{ }^{\circ} \mathrm{C}$ for 1 day. Similar observations are found in the materials exposed to other temperatures and durations. It proves that the proposed HBDT is effective to dissolve the generated crystals (ettringite), due to its thermal instability at temperatures above $65^{\circ} \mathrm{C}$ and its distinguishing phase changes from the other hydration products - ettringite is the main phase that decomposes or changes at temperatures between 65 and $100^{\circ} \mathrm{C}$. The pore space in the pore range of $30-130 \mathrm{~nm}$ is observed to be occupied after being heated, which can be explained by $\mathrm{CH}$ formation, either from the additional hydration or from the decreasing solubility of $\mathrm{CH}$ at high temperatures. After the HBDT, the porosity in the pore range of $30-130 \mathrm{~nm}$ decreases from $12.5 \%$ to around $8.0 \%$. More space with respect to the pores larger than $130 \mathrm{~nm}$ is shown in heated materials due to the occurrence of microcracks, which increases with the increasing temperatures. After being heated at $68^{\circ} \mathrm{C}$, the porosity in the pore range of $130 \mathrm{~nm}-400 \mu \mathrm{m}$ increases from $9.1 \%$ to a value in the range between $10.8 \%$ and $13.3 \%$, and the samples heated at 78,88 , and $98^{\circ} \mathrm{C}$ show a porosity in the range of: $13.2-14.9 \%, 15.3-15.8 \%$, and $13.9-17.8 \%$, respectively. Considering all these factors, a heating at $68^{\circ} \mathrm{C}$ for 1 day is proved to be efficient and effective enough to dissolve the precipitated ettringite, avoiding more microstructural changes in materials that may be generated by higher temperatures and longer heating durations.

However, the "washed out" crystals may not be the only cause of the expansion but also the consequence after the expansion. That is to say, part of the detected ettringite is responsible of the expansion and another part may precipitate after the occurrence of new cracks with no (or minor) deleterious effects. The expansive crystals can not be distinguished from the latter

in this test. Besides the studies of DEF, this HBDT could also be used for other investigations, for example, carbonations or processes inducing any other phases which are sensitive to small temperature variations. 


\section{Acknowledgements}

The technical teams of the FM2D and EMGCU laboratories of the Materials and Structure De-

partment (MAST) of the University Gustave Eiffel are gratefully acknowledged for their support for many measurements.

\section{References}

[1] H. F. W. Taylor, C. Famy, K. L. Scrivener, Delayed ettringite formation, Cement and Concrete Research 31 (5) (2001) 683-693.

[7] D. Damidot, F. P. Glasser, Thermodynamic investigation of the $\mathrm{CaO}-\mathrm{Al}_{2} \mathrm{O}_{3}-\mathrm{CaSO}_{4}-\mathrm{H}_{2} \mathrm{O}$ system at $50^{\circ} \mathrm{C}$ and $85^{\circ} \mathrm{C}$, Cement and Concrete Research 22 (6) (1992) 1179-1191.

[8] I. Odler, Y. Chen, Effect of cement composition on the expansion of heat-cured cement pastes, Cement and Concrete Research 25 (4) (1995) 853-862. 
[19] Y. Gu, Experimental pore scale analysis and mechanical modeling of cement-based materials submitted to delayed ettringite formation and external sulfate attacks, Ph.D. thesis, Université Paris-Est (2018).

[20] R.-P. Martin, F. Toutlemonde, Theoretical and experimental validation of a simple method to

[9] R. Yang, C. Lawrence, C. Lynsdale, J. Sharp, Delayed ettringite formation in heat-cured portland cement mortars, Cement and Concrete Research 29 (1) (1999) 17-25.

[10] C. Lawrence, Long-term expansion of mortars and concretes, Special Publication 177 (1999) $105-124$

[11] C. Famy, Expansion of heat-cured mortars, Ph.D. thesis, Imperial College London (University of London) (1999).

[12] G. Darr, M. Punzet, U. Ludwig, On the chemical and thermal stability of ettringite, in: UInU: Seminar Proceedings, Reaction of Aluminates during the setting of cements, 1997.

[13] N. Skoblinskaya, K. Krasilnikov, Changes in crystal structure of ettringite on dehydration. 1, Cement and Concrete Research 5 (4) (1975) 381-393.

[14] N. Skoblinskaya, K. Krasilnikov, L. Nikitina, V. Varlamov, Changes in crystal structure of ettringite on dehydration. 2, Cement and Concrete Research 5 (5) (1975) 419-431.

[15] C. Lawrence, Mortar expansions due to delayed ettringite formation. Effects of curing period and temperature, Cement and Concrete Research 25 (4) (1995) 903-914.

[16] N. C. Collier, Transition and decomposition temperatures of cement phases-a collection of thermal analysis data, Ceramics-Silikaty 60 (4) (2016) .

[17] M. Castellote, C. Alonso, C. Andrade, X. Turrillas, J. Campo, Composition and microstructural changes of cement pastes upon heating, as studied by neutron diffraction, Cement and Concrete Research 34 (9) (2004) 1633-1644.

[18] EN, 197-1: 2012, Cement, Composition, Specifications and Conformity Criteria for Common Cements

reproduce representative DEF-prone conditions in laboratory, Materials and Structures 46 (8) (2013) 1245-1255. 
[21] T. Ekström, Leaching of concrete, The Leaching Process and Its Effects . (2003) .

[22] Z. Sawicz, Z. Owsiak, Effect of temperatures on the hydrated cement pastes, in: Proceedings of the 5th Symposium on Science and Research in Silicate Chemistry, Brno (Czechoslovakia), 1981, pp. 56-67.

[23] J. I. Escalante-Garcia, J. H., The microstructure and mechanical properties of blended cements hydrated at various temperatures, Cement and Concrete Research 31 (5) (2001) 695-702.

[24] J. Piasta, Z. Sawicz, L. Rudzinski, Changes in the structure of hardened cement paste due to high temperature, Matériaux et Construction 17 (4) (1984) 291-296.

[25] F. S. Rostasy, R. Wei $\beta$, W. G., Changes of pore structure of cement mortars due to temperature, Cement and Concrete Research 10 (2) (1980) 157-164.

[26] S. Diamond, Microstructure of cement-based systems/Bonding and interfaces in cementitious materials, Materials Research Society, 1995.

[27] C. Alonso, L. Fernandez, Dehydration and rehydration processes of cement paste exposed to high temperature environments, Journal of Materials Science 39 (9) (2004) 3015-3024.

[28] W. B. Euler, L. J. Kirschenbaum, B. Ruekberg, Determination of ksp, and for the dissolution of calcium hydroxide in water: A general chemistry experiment 77 (8) (2000) 1039.

[29] T. Van Gerven, G. Cornelis, E. Vandoren, C. Vandecasteele, Effects of carbonation and leaching on porosity in cement-bound waste, Waste Management 27 (7) (2007) 977-985.

[30] K. Haga, S. Sutou, M. Hironaga, S. Tanaka, S. Nagasaki, Effects of porosity on leaching of Ca from hardened ordinary portland cement paste, Cement and Concrete Research 35 (9) (2005) $1764-1775$.

[31] K. Haga, S. Sutou, M. Toyohara, M. Kaneko, Y. Kobayashi, T. Kozawa, Alteration of cement hydrate by dissolution, 1 . alternation test of hydrate cement paste by water-permeation using centrifugal force, Nippon Genshiryoku Gakkai Wabun Ronbunshi 1 (1) (2002) 20-29.

[32] H. Saito, A. Deguchi, Leaching tests on different mortars using accelerated electrochemical method, Cement and Concrete Research 30 (11) (2000) 1815-1825. 
[33] Z. Yan-Rong, K. Xiang-Ming, L. Zi-Chen, L. Zhen-Bao, Z. Qing, D. Bi-Qin, X. Feng, Influence of triethanolamine on the hydration product of portlandite in cement paste and the mechanism, Cement and Concrete Research 87 (2016) 64-76.

[34] R. Cook, K. Hover, Mercury porosimetry of hardened cement pastes, Cement and Concrete Research 29 (6) (1999) 933-943.

[35] M. C. R. Farage, J. Sercombe, C. Galle, Rehydration and microstructure of cement paste after heating at temperatures up to $300{ }^{\circ} \mathrm{C}$, Cement and Concrete Research 33 (7) (2003) 1047-1056. 